\title{
Oxidation or dehydrogenation of alpha-hydroxy acids in bioenergetic metabolism: A murburn perspective
}

\author{
Kelath Murali Manoj ${ }^{1 *}$ \\ ${ }^{1}$ Satyamjayatu: The Science \& Ethics Foundation, \\ Shoranur-2 (PO), Palakkad District, Kerala, India-679122. \\ Email: murman@satyamjayatu.com; (ORCID: 0000-0003-4515-994X)
}

\begin{abstract}
Glycolate, lactate, malate, hydroxyglutarate and isocitrate are key alpha-hydroxyacyl metabolic intermediates found in the tissues/cells/organelles of diverse life forms. They are respectively oxidized to glyoxylate, pyruvate, oxaloacetate, ketoglutarate and oxalosuccinate in cell bioenergetic metabolism. These molecules form key junction points for divergent pathways of two to six carbon-backboned molecules (of various classes of biomolecules like carbohydrates, amino acids, etc.). The oxido-reduction of the alpha-hydroxyacyl species is traditionally believed to be carried out by reversible (de)hydrogenases, employing nicotinamide cofactors. Herein, I propose that while the reductive pathway can be mediated in a facile manner by the (de)hydrogenases, the oxidative reaction could more efficiently be coupled with murzyme activities, which employ diffusible reactive (oxygen) species (DRS/DROS/ROS). Such a murburn strategy would enable the system to tide over the highly unfavorable energy barriers of the sequential dehydrogenase reaction $(\sim 450 \mathrm{~kJ} / \mathrm{mol}$, or more!), to give kinetically viable bimolecular reactions catering to cellular needs. Further, such a scheme does not necessitate any 'intelligent governance' or 'smart decision-making' of/by the pertinent redox enzymes.
\end{abstract}

Keywords: murburn concept; dehydrogenase; transformed Gibbs free energy of reaction in water; alpha hydroxyacid; alpha ketoacid 


\section{Introduction to alpha hydroxyacid metabolism:}

Photorespiration pathways in chloroplasts and plants involving glycolate/glyoxylate; anaerobic glycolysis in muscle and gluconeogenesis in liver; malate shuttle between cytoplasm and mitochondria, etc. and some important steps of Krebs cycle employ enzymes mediating the reversible redox reaction of alpha hydroxyacid to alpha ketoacid. There are usually several isoenzymes involved, which are multimeric and employ the NAD ${ }^{+} / \mathrm{NADH}$ cofactor system. It is assumed that the differences in the isoenzymes' active sites enable these proteins to work the reaction in the forward or reverse directions. Examples of some common enzymes involved are lactate dehydrogenase, malate dehydrogenase, isocitrate dehydrogenase, etc. These enzymes and metabolites serve crucial roles in maintaining the cell metabolic repertoire (Alberts et al., 2002; Berg et al., 2002; Lehninger et al., 2004; Voet \& Voet, 2011).

\section{Identification of a lacuna and a new perspective to interpret the system:}

The fundamental definition of an enzyme does not permit it to alter the equilibrium's position, it can only achieve a reaction mixture attain equilibrium quickly. Therefore, I consider that some of the enzymecatalyzed reactions are essentially irreversible under physiological conditions, and the system must avail alternative reaction strategies to achieve the reverse of a reaction. That is- the system cannot use the same enzyme and the same equation for the forward and backward processes, as it would require the enzyme to be intelligently governed or it must be smart in itself, to deterministically drive outcomes. Since such a scenario is highly unlikely, I propose that the tissues/cells/organelles use alternative strategies to achieve the desired outcomes. Reaction milieu driving the oxidative processes involving such enzymes are usually rich in DROS and I propose that DROS can directly aid the system in oxidation of alpha hydroxyacids to give alpha ketoacid. Therefore, coupling the reactions with murzyme activity (Manoj, 2018; Manoj, 2020) enables thermodynamically and kinetically effective oxidative turnovers. In the particular case, thermodynamics of the pertinent reactions are analyzed in Table 1. For the traditional enzyme catalyzed reaction (A), the transformed Gibbs (standard) free energy of reaction corresponds to $\sim 445$ (lowest positive value) to $\sim 495$ (highest positive value) $\mathrm{kJ} / \mathrm{mol}$, translating to equilibrium constants of $10^{-80}$ to $10^{-87}$. For a simple oxidation alternative proposed in (B), Transformed Gibbs (standard) free energy of reaction corresponds to -88 (lowest negative value) to $\sim-137$ (highest negative value) $\mathrm{kJ} / \mathrm{mol}$, translating to equilibrium constants of $10^{15}$ to $10^{24}$. In the murburn coupled reaction $(\mathrm{C})$, the yield is significantly higher, from -356 to -376

$\mathrm{kJ} / \mathrm{mol}$, corresponding to $\mathrm{K}_{\mathrm{eq}}$ values of $10^{63}$ to $10^{67}$. Therefore, the newly proposed murburn 
coupling reaction strategy affords a high displacement of equilibrium to the right, by a magnitude of $10^{143}$ to $10^{154}$, when compared to the purely (de)hydrogenase enzyme catalyzed reaction!

Table 1: Calculation of overall free energy change in water, for the generic reactions given below:

(A) $\mathrm{R}-(\mathrm{HCOH}) \mathrm{COO}^{-}+\mathrm{NAD}^{+}(1059.1) \leftrightarrow \mathrm{R}-(\mathrm{CO}) \mathrm{COO}^{-}+\mathrm{NADH}(1120.1)+\mathrm{H}^{+}(\mathbf{4 5 2 . 5})$

(B) $\mathrm{R}-(\mathrm{HCOH}) \mathrm{COO}^{-}+\mathrm{O}_{2}(\mathbf{1 6 . 4}) \rightarrow \mathrm{R}-(\mathrm{CO}) \mathrm{COO}^{-}+\mathrm{H}_{2} \mathrm{O}_{2}(-52.5)$

(C) $\mathrm{R}-\mathrm{H}+\mathrm{R}^{\prime}-(\mathrm{HCOH}) \mathrm{COO}^{-}+\mathrm{NADPH}+\mathrm{NAD}^{+}+\mathrm{O}_{2} \rightarrow \mathrm{R}-\mathrm{OH}+\mathrm{R}^{\prime}-(\mathrm{CO}) \mathrm{COO}^{-}+\mathrm{NADP}^{+}+\mathrm{NADH}+\mathrm{H}_{2} \mathrm{O}(-155.7)$

\begin{tabular}{|c|c|c|c|c|c|c|}
\hline \multirow{2}{*}{$\begin{array}{l}\text { No. of carbons, (R) } \\
2,(H)\end{array}$} & \multirow{2}{*}{$\begin{array}{l}\text { Reduced } \\
\text { (hydroxyacid) }\end{array}$} & \multirow{2}{*}{$\begin{array}{l}\begin{array}{l}\text { Oxidized } \\
\text { (ketoacid) }\end{array} \\
\text { Glyoxalate }\end{array}$} & \multicolumn{2}{|c|}{$\begin{array}{c}\Delta_{\mathrm{f}} G^{\prime \mathrm{o}}{ }_{\mathrm{aq}}^{\#} \\
(\mathrm{~kJ} / \mathrm{mol})\end{array}$} & \multirow{2}{*}{$\begin{array}{l}\text { (A) } \Delta_{\mathrm{r}} G^{\prime \mathrm{O}} \mathrm{aq} \\
(\mathrm{kJ} / \mathrm{mol}) \\
492 \pm 3\end{array}$} & \multirow{2}{*}{$\begin{array}{l}(\mathbf{B}, \mathbf{C}) \Delta_{\mathrm{r}} G^{\prime \mathrm{o}} \\
(\mathbf{k J} / \mathrm{mol}) \\
-90,-356\end{array}$} \\
\hline & & & $-(409.5 / 403.3)$ & $-(428.6 / 426.9)$ & & \\
\hline 3, $\left(\mathrm{CH}_{3}\right)$ & Lactate & Pyruvate & $-(313.7 / 301.8)$ & $-(350.8 / 344.8)$ & $473 \pm 4$ & $-109,-375$ \\
\hline 4, $\left(\mathrm{OOC}-\mathrm{CH}_{2}\right)$ & Malate & Oxaloacetate & $-(682.9 / 674.3)$ & $-(715.0 / 712.6)$ & $478 \pm 4$ & $-104,-370$ \\
\hline 5, $\left(\mathrm{OOC}\left(\mathrm{CH}_{2}\right)\left(\mathrm{CH}_{2}\right)\right)$ & Hydroxyglutarate & Ketoglutarate & $-(595 * / 581.6)$ & $-(633.6 / 626.6)$ & $472 \pm 5$ & $-111,-376$ \\
\hline $6,\left(\mathrm{OOC}^{-}\left(\mathrm{CH}_{2}\right)(\mathrm{H}-\mathrm{C}-\mathrm{COO}-)\right)$ & Isocitrate & Oxalosuccinate & $-(959.6 / 952.9)$ & $-(979.1 / 1021.7)$ & $469 \pm 35$ & $-113,-357$ \\
\hline
\end{tabular}

\# Within the parenthesis, the value on the numerator is from Alberty's Handbook and the value on the denominator is from MetCyc website. * Author's approximation. The value given for A is average of the Alberty and MetCyc values, followed by standard deviation. Reaction $B$ is the yield calculated as the average of the Alberty and MetCyc values. Reaction C is calculated from coupling reaction $(A)$ with the generic mixed function oxidase reaction $(D)$ for camphor and diclofenac, giving the hydroxylated products of 5-hydroxycamphor and 4'-hydroxydiclofenac, as follows (predominantly using Alberty values): $\mathrm{RH}(625.6 / 436.4)+\mathrm{O}_{2}(16.4)+\mathrm{NADPH}(237.8) \rightarrow \mathrm{ROH}(458.9 / 271.2)+\mathrm{NADP}^{+}(176.7)+\mathrm{OH}^{-}(-529.1)=-773 /-772 \mathrm{~kJ} / \mathrm{mol}$.

There is a gain of $\sim 79 \mathrm{~kJ} / \mathrm{mol}$, owing to the formation of water (from the fusion of $\mathrm{H}^{+}$and $\mathrm{OH}^{-}$ions), in the combined reaction $(C)$, sum of $(A)$ and $(D)$.

The details of each of these enzyme catalyzed and the materials to support the new proposal shall be provided shortly.

\section{Declarations:}

The author has no conflicts of interests to declare. The work was powered by Satyamjayatu: The Science \& Ethics Foundation. KMM thanks Prof. Nikolai Bazhin (RAS) for discussions.

\section{References:}

Alberts B., Johnson A., Lewis J., et al., Molecular Biology of the Cell 4th edn. (Garland Science, 2002).

Berg J. M., Tymoczko J. L., Stryer L., Biochemistry 5th edn. (W H Freeman, 2002).

Lehninger A.L., Nelson D.L., Cox M., Lehninger: Principles of Biochemistry (Palgrave Macmillan, 2004).

Manoj K.M., The ubiquitous biochemical logic of murburn concept, Biomedical Reviews, 29 (2018), 8997. doi: 10.14748/bmr.v29.5854

Manoj K.M., Murburn concept: A paradigm shift in cellular metabolism and physiology, Biomol. Concepts, 11(2020). doi: 10.1515/bmc-2020-0002

Voet D., Voet J.G. (Eds.) Biochemistry 4th edn, (John Wiley \& Sons, Inc. 2011). 